\title{
Fifty years of reproductive biology in Australia: highlights from the 50th Annual Meeting of the Society for Reproductive Biology (SRB)
}

\author{
Elizabeth G. Bromfield ${ }^{\mathrm{A}}$, Samson N. Dowland ${ }^{\mathrm{B}}$, Jessica E. M. Dunleavy ${ }^{\mathrm{C}}$, \\ Kylie R. Dunning (D) D,E, Olivia J. Holland ${ }^{\mathrm{F}}$, Brendan J. Houston ${ }^{\mathrm{C}}$, \\ Michael W. Pankhurst ${ }^{\mathrm{G}}$, Dulama Richani ${ }^{\mathrm{H}}$, Angelique H. Riepsamen ${ }^{\mathrm{H}}$, \\ Ryan Rose ${ }^{\mathrm{E}, \mathrm{I}}$ and Michael J. Bertoldo (iD H,J,K \\ A Priority Research Centre for Reproductive Science, School of Environmental and Life Sciences, \\ The University of Newcastle, NSW 2308, Australia. \\ ${ }^{\mathrm{B}}$ School of Medical Sciences (Discipline of Anatomy and Histology) and The Bosch Institute, \\ F13 Anderson Stuart Building, The University of Sydney, Sydney, NSW 2006, Australia. \\ ${ }^{\mathrm{C}}$ School of Biological Sciences, Monash University, Clayton, Vic. 3168, Australia. \\ ${ }^{D}$ Australian Research Council Centre of Excellence for Nanoscale BioPhotonics, \\ University of Adelaide, SA 5005, Australia. \\ ${ }^{E}$ Robinson Research Institute, Adelaide Medical School, University of Adelaide, Adelaide, \\ SA 5005, Australia. \\ ${ }^{\mathrm{F}}$ School of Medical Science, Griffith University, Gold Coast Campus, Southport, Qld 5005, \\ Australia. \\ ${ }^{\mathrm{G}}$ Department of Anatomy, School of Biomedical Sciences, University of Otago, Dunedin 9054, \\ New Zealand.

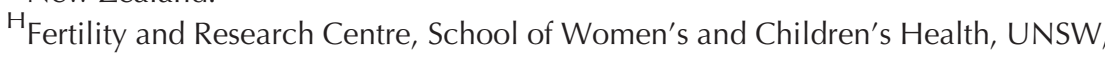 \\ Randwick 2052, NSW 4222, Australia. \\ 'Fertility SA, St. Andrews Hospital, South Terrace, Adelaide, SA 5000, Australia. \\ ${ }^{J}$ School of Medical Sciences, UNSW, Randwick, NSW 2052, Australia. \\ ${ }^{K}$ Corresponding author. Email: michael.bertoldo@unsw.edu.au
}

\begin{abstract}
The 2018 edition of the Society for Reproductive Biology's (SRB) Annual Meeting was a celebration of 50 years of Australian research into reproductive biology. The past 50 years has seen many important contributions to this field, and these advances have led to changes in practice and policy, improvements in the efficiency of animal reproduction and improved health outcomes. This conference review delivers a dedicated summary of the symposia, discussing emerging concepts, raising new questions and proposing directions forward. Notably, the symposia discussed in this review emphasised the impact that reproductive research can have on quality of life and the health trajectories of individuals. The breadth of the research discussed encompasses the central regulation of fertility and cyclicity, life course health and how the environment of gametes and embryos can affect subsequent generations, significant advances in our understanding of placental biology and pregnancy disorders and the implications of assisted reproductive technologies on population health. The importance of a reliable food supply and protection of endangered species is also discussed. The research covered at SRB's 2018 meeting not only recognised the important contributions of its members over the past 50 years, but also highlighted key findings and avenues for innovation moving forward that will enable the SRB to continue making significant contributions for the next 50 years.
\end{abstract}

Additional keywords: assisted reproduction, fetal programming, fertility, gamete, gestation, implantation, placenta, preterm birth.

Received 29 October 2018, accepted 3 December 2018, published online 14 January 2019 


\section{Introduction}

Over the past 50 years of progress in the field of reproductive science, the Society for Reproductive Biology (SRB) has held a solid footing in diverse aspects of reproduction and fertility, with strengths in both male and female reproductive physiology, gamete quality, periconceptual health and placentation. Importantly, the intense study of domestic animal reproduction during the founding years of the society has not only allowed for innovation and progress in an agricultural context, but has also provided a platform for the SRB to contribute new knowledge to guide practises and innovations in assisted reproduction that now feature so heavily in modern reproductive health. This review serves to highlight the progress made in reproductive biology during this time and draws a focus to both enduring and emerging issues of reproduction and fertility that will require our attention in the future.

\section{Fifty years of reproductive biology in Australia I}

\section{Speakers: John Hearn, Mark Hedger, Darryl Russell, Lois Salamonsen, Sarah Robertson}

John Hearn, previous president of the SRB, explored the growth of the society from its original focus on sheep and marsupials to its current state encompassing all aspects of reproductive biology. At the conception of the society in 1968 , there was a strong focus on ovarian and oocyte biology, the endocrinology of the ovary and hypothalamic and pituitary control of reproduction. A major Australian contribution to the latter endeavour was the isolation and characterisation of inhibin in 1986 (Robertson et al. 1986), with subsequent discovery and functional analyses of the related activins. In relation to oocyte biology, despite significant improvements in our understanding of oocyte maturation and ovarian function, it remains unclear why some oocytes do not develop into viable blastocysts. Exciting current research is uncovering how events in oocyte maturation influence the embryo (Robker et al. 2018).

Our understanding of steroid and pituitary hormone functions in endometrial cycles expanded in the 1960-70s with the advent of suitable assays. The endometrium produces many signalling molecules that drive its cyclical remodelling, enabling the embryo to implant and a placenta to develop. Although oestrogen and progesterone, along with the pituitary hormones, are important regulators of a woman's reproductive cyclicity, the exogenous hormones used in infertility clinics during ovarian stimulation are detrimental to uterine function and establishing pregnancy (Lindsay et al. 2016). Lessons learnt about the endometrial contribution to optimal blastocyst development within the uterine cavity could lead to further improvement of embryo culture techniques (Xiao et al. 2017). Interestingly, menstrual fluid contains unique factors that promote endometrial repair after menstruation, and these also promote wound healing (Evans et al. 2018), opening up novel avenues of research.

Many fundamental uterine regulators are shared with immunity and provide mechanisms for interactions between the immune and reproductive systems. This has been a challenge to understand given that the paternal contribution to the fetal genome may be expected to induce rejection of the fetus. For most of the latter half of the 20th century, it was mistakenly thought that viviparity defies the immune system by escaping maternal immune recognition (Billington 2003). However, the immune system is now known to be an active participant in healthy pregnancy and in the mechanisms of miscarriage. Regulatory $\mathrm{T}$ cells (Tregs) play a vital role in establishing maternal immune tolerance to the fetus (Guerin et al. 2009). Australian researchers have played a key role in demonstrating that this process begins before pregnancy, because regulatory $\mathrm{T}$-cells respond to the components of seminal fluid to induce tolerance of paternal antigens (Robertson et al. 2013). It is now clear that the immune and reproductive systems work in partnership, rather than in opposition, ensuring the maintenance of genetic diversity in outbred populations. These discoveries have enabled key advancements in our understanding of female fertility and uterine function in women.

The description of the blood-testis barrier and testicular fluid movement were significant achievements of the late 1960s. The major advancements over the next two decades largely related to the characterisation of testicular function and the causes of reproductive conditions caused by dysfunction. In the early 1990s, potential male contraceptives were being explored, yet these still remain elusive 25 years later. In 1994 there was much debate regarding the use of intracytoplasmic sperm injection (ICSI), which was lauded as the solution to all male infertility. However, the lasting effects of this technology are still not clear, and the selection of spermatozoa with good-quality DNA remains an important challenge. There remain many threats to male fertility, with declining sperm count and quality alongside increasing pathologies and infections. Current research in the SRB is investigating the role of genetics, environment, obesity and diagnostics of fertility in an attempt to meet these rising challenges.

\section{0 years of reproductive biology in Australia II}

\section{Speakers: Marilyn Renfree, Christopher Grupen, Roger Smith, Jock Findlay}

Over the past 50 years, breakthroughs in large animal biotechnology have allowed scientists and animal producers to feed our growing populations. Multiple ovulation and embryo transfer were key to the rapid dissemination of valuable genetic material in cattle, and this was achieved through successful collaborations between researchers and veterinary practitioners in the early years of assisted reproduction. During the 1970s, 1980s and 1990s, significant contributions from Australian scientists included the development of synthetic oviductal fluid for ruminant embryo culture (Tervit et al. 1972), offspring from IVF of oocytes derived from juvenile animals (Armstrong et al. 1997), development of defined culture media (Gardner et al. 1994) and the first lamb from sex-sorted spermatozoa (Catt et al. 1996). This period was followed by the advent of transgenesis; today, cloning and gene editing technologies are increasingly being used in livestock species to advance our understanding of agricultural traits, as well as the production of pharmaceuticals and models of human disease. In animal breeding and genetic 
improvement programs, AI and embryo transfer now play such integral roles that nearly all the food we consume is derived from some form of reproductive biotechnology.

Marsupials have been prominent in Australian reproductive sciences over the past 50 years. Marsupials have elaborated lactation over placentation and have evolved a very sophisticated lactation physiology that allows them to produce a milk that continuously changes its composition throughout pouch life (Trott et al. 2003). This adaptation allows the mother to cater for the developmental stage of the offspring. We now know that the composition of milk has a profound effect on development, and fostering young to later-stage milk accelerates growth (Hetz et al. 2016). Marsupial milk contains many bioactives, including some cathelicidins that inhibit multiresistant Staphylococcus aureus, and others that affect the development of the lungs. Because lactation is such a critical mammalian characteristic, controlling not only the development of the young, but also reproduction, it is surprising that more research in these species is not currently underway.

\section{Assisted reproductive technologies \\ Speakers: David Whittingham, Alan Trounson, Robert Norman}

Assisted reproductive technology (ART) is the culmination of numerous advances in basic biology, reproductive endocrinology and development. Four major areas pioneered the conception and birth of the first IVF baby, Louise Brown, in 1978: the collection of mature and developmentally competent oocytes, fertilisation, the culture of preimplantation embryos and replacement of these embryos back into the mother (Biggers 2012). Due to the lack of knowledge and belief that IVF should be developed in humans, small mammals were vital to our early successes (Chang 1959; Whittingham 1968), where subsequent advances caught the eye of domestic animal industries (cattle, sheep, horses and pigs) and became progressively valuable. This session highlighted Australia's contribution to the human reproductive revolution, including the first biochemical pregnancy from IVF (De Kretzer et al. 1973), as well as pregnancies from controlled ovulatory cycles (Trounson et al. 1981) and the first pregnancy from a cryopreserved embryo (Trounson and Mohr 1983). Furthermore, ART was instrumental in the development of alternative technologies, including cloning, stem cells and regenerative medicine. Further development of these technologies has led to recent innovations in stem cell therapies like chimeric antigen receptor technologies (CAR-T) for the treatment of cancer and potentially the treatment of antibioticresistant infections (Maldini et al. 2018).

Millions of children have now been born using ART, yet significant challenges remain, including the poor success rates in women of advanced maternal age, unexplained implantation failure and recurrent miscarriage and reports of undesirable health outcomes for children conceived from ART. With the rapid advancement of ART, the growing acceptance of reproductive technology and the commercialisation of IVF, we require strict guidelines for quality management of procedures, clinicians and scientists to maintain high standards and equity of care.

\section{Male reproduction}

Speakers: David Handelsman, John Aitken, Rob McLachlan, Elizabeth Bromfield

Over the past 50 years, male reproductive issues have matured into a mainstream concern within the wider fertility field. Infertility is no longer considered exclusively 'a woman's problem', with the importance of male reproductive health for both fertility and offspring health now well recognised.

One of the biggest triumphs in the field has been in endocrinology, with the disentangling of the male hypothalamicpituitary-gonadal (HPG) axis. It is now well established that, in males, testosterone, driven by gonadotrophin-releasing hormone $(\mathrm{GnRH})$ and $\mathrm{LH}$, is essential to initiate and maintain spermatogenesis. Moreover, the previous dogma that FSH is also essential for spermatogenesis has been convincingly disproven via several gene knockout models. Understanding the HPG axis has allowed both effective treatment of HPG disorders and the proposal of multiple contraceptive strategies, which take advantage of the testosterone negative feedback loop to induce reliable and reversible azoospermia (for a review, see Khourdaji et al. 2018). Looking forward, there are concerns about the current state of steroid immunoassays, because increasing drive towards greater throughput of assays has detracted from their reliability, resulting in a loss of accuracy in testosterone measurement in clinical and experimental settings (Handelsman et al. 2015), and the wider use of steroid mass spectrometry is needed. Although there are important opportunities for androgen therapy to improve quality of life in certain pathologies that warrant exploration, there is also a large and growing tide of androgen misuse and abuse for medical and cosmetic misapplications respectively that needs to be curbed.

In Australia and New Zealand, one in 20 males of reproductive age is infertile. Environment, lifestyle, age and several disease states negatively affect male fertility, and there is now a large body of evidence to indicate oxidative stress is often the 'common end' to these diverse factors. Spermatozoa are uniquely sensitive to oxidative stress because their membranes are highly enriched in polyunsaturated fatty acids that are key substrates for oxidative attack and they possess minimal cytoplasmic antioxidant content. As such, lipid peroxidation and its downstream cytotoxic products are common in male subfertility. One of the most damaging lipid peroxidation products produced in the male germline is 4-hydroxynonenal (4HNE), a lipid aldehyde that can cause DNA and protein damage and is increased in men with idiopathic infertility, as well as in patients with varicocoele-induced infertility. One new strategy to reduce $4 \mathrm{HNE}$ production is through the inactivation of lipoxygenase enzymes that have recently been shown to contribute to oxidative stress in human spermatozoa (Walters et al. 2018).

ARTs such as IVF and ICSI have revolutionised male infertility treatment. However, there are increasing concerns regarding the overuse and reliance on such techniques. Many aspects of IVF and ICSI are conducive, for example, to the generation of oxidative damage in both spermatozoa and the developing embryo, and significant increases in the incidence of congenital malformations have been reported in ART offspring 
(Wen et al. 2012; Giorgione et al. 2018). There are particular concerns regarding ICSI, because it evades many important quality control mechanisms that prevent, for example, DNAdamaged spermatozoa from achieving fertilisation (Aitken and Krausz 2001).

Genetic abnormalities also underlie a significant number of infertility cases, and Australian researchers have been major players in identifying and understanding genetic-based male infertility. The establishment of the Monash Male Infertility Database has been an invaluable resource in this regard, and thus far clinical and genomic data from more than 2500 men have been collected. The recent formation of the International Male Infertility Genomics Consortium (IMIGC) will lead this area into the future through its multidisciplinary approach, integrating clinical and genomic analysis of several international infertility patient databases. Overall, uncovering fundamental aspects of male reproduction has allowed researchers to pursue many concerning factors that contribute to infertility, and will ultimately drive innovative solutions to address issues of male reproductive health in the future.

\section{Female reproduction}

\section{Speakers: Iain Clarke, Ray Rodgers, Graeme Martin, Karla Hutt}

The past 50 years have seen significant advances in our understanding of ovarian biology due, in part, to the advent of techniques such as IVF, cryopreservation, hormone radioimmunoassays and genome editing. These new insights have paved the way for translational research to improve health outcomes.

The first radioimmunoassay for sheep LH was reported in 1969 (Goding et al. 1969) and, given the value of the sheep as a model, helped shape our understanding of neuroendocrine control of female reproduction over the next 50 years. The development of the transsphenoidal approach to sample hypophyseal circulation in sheep verified the role of GnRH in the induction of pulsatile $\mathrm{LH}$ and validated the use of $\mathrm{LH}$ pulses as a 'bioassay' of the activity of brain GnRH neurons and the role of these cells as a final common pathway in the control of the reproductive axis (Clarke and Cummin 1982). With the discovery of additional endocrine and neuroendocrine regulators (e.g. inhibin, leptin, gonadotrophin-inhibiting hormone, kisspeptin), the transsphenoidal (hypothalamic-pituitary collection) model was pivotal in differentiating between hypothalamic and pituitary sites of action for each regulator (Clarke et al. 1983). Thus, the measurement of GnRH and LH pulses in sheep models became valuable in determining the effects of pheromones (Martin et al. 1980), day length and stress on female reproductive cyclicity. These experiments demonstrated that the brain responds to season, nutritional status and the relative safety of the animal with consequent effects on reproduction (Martin et al. 2004). We now understand that a series of conditions must be met before the brain provides permission for reproduction to proceed in the form of gonadotrophin secretion and cyclicity. These insights demonstrate that animal breeding can be managed in a non-invasive manner by manipulating the animal's environment (Martin et al. 2004).
New knowledge into the development of the ovary has also emerged. A new somatic cell type of the mesonephros, gonadal ridge epithelial-like (GREL) cells, was identified as the progenitor to ovarian granulosa and epithelial cells (Hummitzsch et al. 2013). Formation of follicles takes place when stroma penetrates the primordium, forming many ovigerous cords made up of primordial germ and GREL cells. The association of these two cell types leads to follicle formation, with GREL cells differentiating into granulosa cells. These findings highlight the importance of stromal activity in ovary formation, and bring new insight into the aetiology of polycystic ovary syndrome (PCOS), a condition known to have aberrant stromal formation.

Over the past five decades, cancer survival rates have improved markedly, inviting the need to preserve the fertility of patients. Chemotherapy leads to the depletion of ovarian follicles. However, current fertility preservation techniques involve the cryopreservation of oocytes, embryos or ovarian cortical tissue, all with variable success. Many working in oncofertility research are now turning their attention to the development of drugs that can prevent initial oocyte damage, thus preserving the ovarian follicle pool as well as ovarian endocrine function. Recent evidence suggests that cancer therapies reduce the primordial follicle pool by promoting DNA damage and apoptosis in their oocytes (Winship et al. 2018). The proapoptotic protein $\mathrm{p} 53$ upregulated modulator of apoptosis (PUMA) was identified as critical apoptotic trigger in ovarian reserve depletion following chemotherapy. In this way, Pumaknockout mice are not susceptible to chemotherapy-induced loss of ovarian reserve or fertility (Nguyen et al. 2018). This suggests that pharmacological targets of apoptosis may be effective ovoprotectants during cancer treatment.

\section{Periconceptional environment}

\section{Speakers: Mary Wlodek, Michelle Lane, Patrick Western, Karen Moritz}

At sensitive stages of development, we undergo programming such that we respond to environmental stressors in a way that predicts our health and risk of non-communicable disease throughout the life course. Although life in utero is important, the environment in which the gametes and early embryo develop is also critical in determining the lifelong health of offspring.

Effects of environmental stressors, including obesity, maternal stress or anxiety and depression, are not restricted to the first affected generation, but are transmitted in subsequent, unexposed generations (Dickinson et al. 2016). In determining the underlying mechanisms of this transgenerational effect, recent focus has been placed on adolescence. Health, nutrition and socioeconomic factors during this stage affect the development of gametes and lay foundations for the health of the next generation (Patton et al. 2018). Thus, investment in research to develop effective interventions during adolescence will likely lead to improved health for subsequent generations. Maternal overnutrition and obesity are known to be associated with adverse pregnancy complications and predispose the offspring to later-life metabolic 
disturbances. More recently, maternal and paternal lifestyle factors before and around the time of conception have been shown to affect the health of subsequent generations (Lane et al. 2015). The combined effect of having an obese mother and obese father results in the embryo inheriting negative alterations from both gametes, including mitochondrial dysfunction and increased intracellular lipid from the oocyte and altered chromatin from the spermatozoon (McPherson et al. 2015). The removal of gametes from an obesogenic environment and their culture in an optimal in vitro system could potentially reverse these effects.

The transmission of information from the gametes to the resultant embryo and offspring is likely due to altered epigenetic modifications in the oocyte and spermatozoon that avoid, in part, epigenetic reprogramming at fertilisation. The inheritance of required epigenetic information necessitates epigenetic marks to be reset during the development of the germ cells (Hogg and Western 2015). During epigenetic reprograming, germ cells contain abundant levels of trimethylated lysine 27 of histone $\mathrm{H} 3$ (H3K27 me3), which is reorganised in an enhancer of zeste homolog 2 (EZH2)-dependent manner (Prokopuk et al. 2017). In mice, inhibition of EZH1/2 with tazemetostat, a drug in clinical trials for cancer treatment, results in a significant reduction in $\mathrm{H} 3 \mathrm{~K} 27$ me 3 in growing oocytes that is not restored after treatment (Prokopuk et al. 2018a). Moreover, loss of H3K27 me3 in the oocyte alters offspring growth, bone mineral density, muscle and fat content, indicating that $\mathrm{H} 3 \mathrm{~K} 27$ me 3 in the oocyte is important for outcomes in offspring (Prokopuk et al. 2018b). However, whether tazemetostat and similar drugs affect the epigenome of the germline in a transient manner or have long-lasting effects that are transmitted to future generations requires further investigation such that appropriate clinical guidelines are established for their use in patients of reproductive age (Western 2018).

Although promotion of the health message to avoid alcohol entirely during pregnancy is widespread, maternal consumption of alcohol continues for many, particularly before pregnancy has been identified. Alcohol exposure alters the maternal environment, including nutrient status. It also results in epigenetic modifications, altered preimplantation embryo development and placental function (Kalisch-Smith and Moritz 2018). A recent systematic review of clinical and preclinical studies indicates that dietary supplementation with choline partially reverses the effects of alcohol on offspring health (Akison et al. 2018). The concentration of alcohol and altered milieu experienced by the gametes and the early preimplantation embryo in the reproductive tract requires further investigation such that appropriate models can be developed to interrogate the effectiveness of novel interventions (Kalisch-Smith and Moritz 2018). Future research efforts in understanding how the periconception environment affects lifelong health should focus on determining the mechanisms underlying the programming of transgenerational disease. This will reveal the windows of plasticity where interventions, whether they be lifestyle, pharmacological or in vitro manipulations, will result in the development of healthy, resilient offspring.

\section{Placental biology and pregnancy disorders}

\section{Speakers: Claire Roberts, Kirsty Pringle, James Cuffe and Natalie Hannan}

The placenta is fundamental to pregnancy health. This session explored the history of placental research and how knowledge about this critical organ has advanced our understanding of pregnancy complications.

Pre-eclampsia has remained a central research theme. Pioneering work in the 1970s and 1980s found the first evidence of inadequate uterine spiral artery remodelling in pre-eclampsia. More recently, the complexity of oxygen-related signalling and blood flow to the placenta has become better appreciated, as has the role of the placental renin-angiotensin system in preeclampsia (Pringle et al. 2010; Delforce et al. 2016). Therefore, perturbations to maternal-placental blood flow or oxygen, along with the effects of an aberrant maternal immune response to pregnancy, are still thought to be central to the pathophysiology of pre-eclampsia.

The symptoms of pre-eclampsia have long been hypothesised to be caused by a placental toxin(s) in the maternal circulation. One candidate factor identified is soluble fms-like tyrosine kinase-1 (sFlt-1). Blocking sFlt-1 production in the placenta may improve pre-eclampsia prognosis, and several potential treatments, including esomeprazole, are under investigation (Onda et al. 2017). A recent very large trial using lowdose aspirin showed a reduced incidence of pre-eclampsia in the treated group (Rolnik et al. 2017). In addition, sildenafil has been tested in women carrying a severely growth-restricted fetus in an attempt to improve placental vasodilation. However, trials have been suspended due to increased perinatal mortality (Smith 2018). Overall, our understanding of how to treat pre-eclampsia still has many unknowns that require ongoing research.

Cross-talk between maternal-placental-fetal systems and the environment is now a major focus of research, and highlights that the placenta is likely central to programming disease in offspring. Animal models have demonstrated that pregnancy can act as a 'second hit' and unmask diseases such as gestational diabetes that can impair maternal health after pregnancy and have intergenerational consequences (Cheong et al. 2016). With placental dysfunction central to the pathologies associated with pregnancy disorders, it is important to consider how events before pregnancy, even during fetal development, may affect maternal health. It is also becoming clear that interactions between parental genes and the environment influence changes in fetal and placental gene expression, and have key roles in maternal and offspring health (Roberts 2010). The placenta is now appreciated as a dynamic organ that coordinates significant maternal physiological adaptations. Understanding the links between placental dysfunction and pregnancy complications continues to help unravel the pathophysiology of these disorders.

\section{Reproductive Health Australia Symposium}

Speakers: Sarah Robertson, Jeremy Thompson and Andrew Pask

In 2018 we saw the launch of Reproductive Health Australia, an alliance between Australian reproductive biologists from all 
fields of research that focuses on promoting the health, economic and social benefits of reproductive health and research. The Reproductive Health Australia initiative has been formally launched to strengthen and recognise Australia's reputation and success for research in reproductive science. As such, the Reproductive Health Australia symposium demonstrated how broadly reproductive biology can affect our lives and tackled three major issues underpinned by reproductive health and success: human fertility, meat production and wildlife conservation and management. A major theme linking these topics was the importance of investing in early life events, such as gamete quality and periconceptional health, as the most beneficial approach for both a healthy life trajectory and preserving genetic diversity.

Australian fertility rates are at a 10-year low and are now below the replacement rate ( 1.8 children born per woman). This phenomenon is occurring worldwide in developed countries alongside a significant decline in sperm counts. Although IVF is a successful strategy to address infertility, it does not address underlying causes. Events occurring during conception and pregnancy program the trajectory of the lifelong health of an individual. Controlling the incidence of non-communicable diseases will also likely revolve around early origins of health and disease through reproductive programming. One challenge will be dissecting the relationship between genetics and environmental factors in the context of human fertility.

The Australian red meat industry is faced with many efficiency challenges to meet increasing global demand of quantity and quality product while reducing the effect on the environment, particularly greenhouse gas emissions, and heat stress in livestock by breeding heat- and drought-tolerant animals. ARTs can meet such challenges by enabling focused genetic selection technologies. However, methods for sheep and cattle selection are male focused (e.g. AI). To meet future demands, rapid genetic diversity is required using simultaneous female and male genetic selection. IVF offers the most flexibility to enable this. IVF in conjunction with genetic testing is set to change how we rapidly breed more efficient livestock that are better able to meet environmental challenges. Developing technologies to identify the IVF embryos with high pregnancy capacity and educating veterinarians about advanced ARTs are two essential goals for this field.

Australia is one of the 18 megadiverse countries in the world, home to a range of diverse and unique species. However, more than $20 \%$ of all native land mammals suffer the threat of extinction, and many exotic pest species are rampant in Australia, burdening us with significant economic costs and resource competition for native species. It is clear that targeting reproduction in both cases is a strong approach. Structured breeding has shown promise with Tasmanian devils resistant to the devil facial tumour and pygmy possum populations with low genetic diversity. Meanwhile, the extreme fecundity of female cane toads renders classical approaches unfeasible and has driven researchers to develop new methods for the control of reproduction. Clustered regularly interspaced short palindromic repeat (CRISPR) technology can be used to bias the inheritance of modified genes and will potentially aid in the development of daughterless toads in the future.
Future advances in the field of human fertility will require us to alter the misconception that reproductive research is focused towards increasing world population. However, this paradigm change requires researchers to explain the broader benefits and rationale of this research, to know the evidence and challenge inaccuracies.

\section{Conclusion}

The 2018 SRB annual conference highlighted the important contributions of its members to the field of reproductive biology over the past 50 years, and the translation of those contributions for better outcomes in health, food security and the protection of endangered species. However, none of this would have been possible without reliable funding for basic and applied scientists in the field. Clearly this support needs to continue into the future. Importantly, several presentations demonstrated the effects of periconception and prenatal environment on the life course health of offspring. As in previous SRB meetings (Bertoldo et al. 2018), there is ongoing research into the well-being of offspring conceived via ART to ensure that Australian clinics are at the forefront of best practice to support the ongoing health of individuals. The 2018 SRB meeting was the launching pad for the Reproductive Health Australia imitative, a first of its kind in Australia, and it is hoped that this initiative will assist in advocating for reproductive research to take the Society forward for another 50 years.

\section{Conflicts of interest}

The authors declare no conflicts of interest.

\section{Acknowledgements}

The authors acknowledge the following speakers who presented their research in the symposia and thank them for supplying their talks: John Hearn, Christopher Grupen, David Handelsman (University of Sydney); Mark Hedger, Lois Salamonsen, Jock Findlay, Alan Trounson, Robert McLachlan, Patrick Western (Hudson Institute of Medical Research); Darryl Russell, Sarah Robertson, Robert Norman, Claire Roberts, Raymond Rodgers, Michelle Lane, Jeremy Thompson (University of Adelaide); Marilyn Renfree, Natalie Hannan, Mary Wlodek, Andrew Pask (The University of Melbourne); Roger Smith, John Aitken, Elizabeth Bromfield, Kirsty Pringle (University of Newcastle); David Whittingham (University of Cambridge); James Cuffe, Karen Moritz (University of Queensland); Iain Clarke, Karla Hutt (Monash University); and Graeme Martin (University of Western Australia). The authors also acknowledge the SRB President Moira O'Bryan, past President Christopher O'Neill and the Editor-in-Chief of Reproduction, Fertility and Development, Graeme Martin, for their support of the SRB Early Career Researchers and this review. Kylie R. Dunning was supported by the Australian Research Council (CE140100003).

\section{References}

Aitken, R. J., and Krausz, C. (2001). Oxidative stress, DNA damage and the Y chromosome. Reproduction 122, 497-506. doi:10.1530/REP.0. 1220497

Akison, L. K., Kuo, J., Reid, N., Boyd, R. N., and Moritz, K. M. (2018). Effect of choline supplementation on neurological, cognitive, and behavioral outcomes in offspring arising from alcohol exposure during development: a quantitative systematic review of clinical and preclinical studies. Alcohol. Clin. Exp. Res. 42, 1591-1611. doi:10.1111/ACER. 13817 
Armstrong, D. T., Kotaras, P. J., and Earl, C. R. (1997). Advances in production of embryos in vitro from juvenile and prepubertal oocytes from the calf and lamb. Reprod. Fertil. Dev. 9, 333-339. doi:10.1071/ R96080

Bertoldo, M. J., Andraweera, P. H., Bromfield, E. G., Cousins, F. L., Lindsay, L. A., Paiva, P., Regan, S. L., Rose, R. D., and Akison, L. K. (2018). Recent and emerging reproductive biology research in Australia and New Zealand: highlights from the Society for Reproductive Biology Annual Meeting, 2017. Reprod. Fertil. Dev. 30, 1049-1054. doi:10. 1071/RD17445

Biggers, J. D. (2012). IVF and embryo transfer: historical origin and development. Reprod. Biomed. Online 25, 118-127. doi:10.1016/J. RBMO.2012.04.011

Billington, W. D. (2003). The immunological problem of pregnancy: 50 years with the hope of progress. A tribute to Peter Medawar. J. Reprod. Immunol. 60, 1-11. doi:10.1016/S0165-0378(03)00083-4

Catt, S. L., Catt, J. W., Gomez, M. C., Maxwell, W. M. C., and Evans, G. (1996). Birth of a male lamb derived from an in vitro matured oocyte fertilised by intracytoplasmic injection of a single presumptive male sperm. Vet. Rec. 139, 494-495. doi:10.1136/VR.139.20.494

Chang, M. C. (1959). Fertilization of rabbit ova in vitro. Nature 184, 466467. doi:10.1038/184466A0

Cheong, J. N., Wlodek, M. E., Moritz, K. M., and Cuffe, J. S. (2016). Programming of maternal and offspring disease: impact of growth restriction, fetal sex and transmission across generations. J. Physiol. 594, 4727-4740. doi:10.1113/JP271745

Clarke, I. J., and Cummins, J. T. (1982). The temporal relationship between gonadotropin releasing hormone $(\mathrm{GnRH})$ and luteinizing hormone $(\mathrm{LH})$ secretion in ovariectomized ewes. Endocrinology 111, 1737-1739. doi:10.1210/ENDO-111-5-1737

Clarke, I. J., Cummins, J. T., and de Kretzer, D. (1983). Pituitary gland function after disconnection from direct hypothalamic influences in the sheep. Neuroendocrinology 36, 376-384. doi:10.1159/000123484

De Kretzer, D., Dennis, B., Leeton, J., Lopata, A., Outch, K., Talbot, J., and Wood, C. (1973). Transfer of a human zygote. Lancet 302, 728-729. doi:10.1016/S0140-6736(73)92553-1

Delforce, S. J., Wang, Y., Van-Aalast, M. E., Corbisier de Meaultsart, C., Morris, B. J., Broughton-Pipkin, F., Roberts, C. T., Lumbers, E. R., and Pringle, K. G. (2016). Effect of oxygen on the expression of reninangiotensin system components in a human trophoblast cell line. Placenta 37, 1-6. doi:10.1016/J.PLACENTA.2015.11.011

Dickinson, H., Moss, T. J., Gatford, K. L., Moritz, K. M., Akison, L. K., Fullston, T., Hryciw, D. H., Maloney, C. A., Morris, M. J., Wooldridge, A. L., Schjenjen, J. E., Roberston, S. A., Waddell, B. J., Mark, P. J., Wyrwoll, C. S., Ellery, S. J., Thornburg, K. L., Muhlhausler, B. S., and Morrison, J. L. (2016). A review of fundamental principles for animal models of DOHaD research: an Australian perspective. J. Dev. Orig. Health Dis. 7, 449-472. doi:10.1017/S2040174416000477

Evans, J., Infusini, G., McGovern, J., Cuttle, L., Webb, A., Nebl, T., Milla, L., Kimble, R., Kempf, M., Andrews, C. J., Leavesley, D., and Salamonsen, L. A. (2018). Menstrual fluid factors facilitate tissue repair: identification and functional action in endometrial and skin repair. FASEB J. doi:10.1096/FJ.201800086R

Gardner, D. K., Lane, M., Spitzer, A., and Batt, P. A. (1994). Enhanced rates of cleavage and development for sheep zygotes cultured to the blastocyst stage in vitro in the absence of serum and somatic cells: amino acids, vitamins, and culturing embryos in groups stimulate development. Biol. Reprod. 50, 390-400. doi:10.1095/BIOLREPROD50.2.390

Giorgione, V., Parazzini, F., Fesslova, V., Cipriani, S., Candiani, M., Inversetti, A., Sigismondi, C., Tiberio, F., and Cavoretto, P. (2018). Congenital heart defects in IVF/ICSI pregnancy: systematic review and meta-analysis. Ultrasound Obstet. Gynecol. 51, 33-42. doi:10.1002/ UOG. 18932
Goding, J. R., Catt, K. J., Brown, J. M., Kaltenbach, C. C., Cumming, I. A., and Mole, B. J. (1969). Radioimmunoassay for ovine luteinizing hormone. Secretion of luteinizing hormone during estrus and following estrogen administration in sheep. Endocrinology 85, 133-142. doi:10. 1210/ENDO-85-1-133

Guerin, L. R., Prins, J. R., and Roberston, S. A. (2009). Regulatory T-cells and immune tolerance in pregnancy: a new target for infertility treatment? Hum. Reprod. Update 15, 517-535. doi:10.1093/HUMUPD/ DMP004

Handelsman, D. J., Jimenez, M., Singh, G. K., Spaliviero, J., Deasi, R., and Walters, K. A. (2015). Measurement of testosterone by immunoassays and mass spectrometry in mouse serum, testicular, and ovarian extracts Endocrinology 156, 400-405. doi:10.1210/EN.2014-1664

Hetz, J. A., Menzies, B. R., Shaw, G., Stefanidis, A., Cowley, M. A., and Renfree, M. B. (2016). Effects of nutritional manipulation on body composition in the developing marsupial, Macropus eugenii. Mol. Cell. Endocrinol. 428, 148-160. doi:10.1016/J.MCE.2016.03.030

Hogg, K., and Western, P. S. (2015). Refurbishing the germline epigenome: out with the old, in with the new. Semin. Cell Dev. Biol. 45, 104-113. doi:10.1016/J.SEMCDB.2015.09.012

Hummitzsch, K., Irving-Rodgers, H. F., Hatzirodos, N., Bonner, W., Sabatier, L., Reinhardt, D. P., Sado, Y., Ninomiya, Y., Wilheim, D., and Rodgers, R. J. (2013). A new model of development of the mammalian ovary and follicles PLoS One 8, e55578. doi:10.1371/ JOURNAL.PONE.0055578

Kalisch-Smith, J. I., and Moritz, K. M. (2018). Detrimental effects of alcohol exposure around conception: putative mechanisms. Biochem. Cell Biol. 96, 107-116. doi:10.1139/BCB-2017-0133

Khourdaji, I., Zillioux, J., Eisenfrats, K., Foley, D., and Smith, R. (2018) The future of male contraception: a fertile ground. Transl. Androl. Urol. 7, S220-S235. doi:10.21037/TAU.2018.03.23

Lane, M., Zander-Fox, D. L., Robker, R. L., and McPherson, N. O. (2015) Peri-conception parental obesity, reproductive health, and transgenerational impacts. Trends Endocrinol. Metab. 26, 84-90. doi:10.1016/J. TEM.2014.11.005

Lindsay, L. A., Dowland, S. N., and Murphy, C. R. (2016). Uterine focal adhesions are retained at implantation after rat ovarian hyperstimulation. Reproduction 152, 753-763. doi:10.1530/REP-16-0331

Maldini, C. R., Ellis, G. I., and Riley, J. L. (2018). CAR T cells for infection, autoimmunity and allotransplantation. Nat. Rev. Immunol. 18, 605-616. doi:10.1038/S41577-018-0042-2

Martin, G. B., Oldham, C. M., and Lindsay, D. R. (1980). Increased plasma LH levels in seasonally anovular merino ewes following the introduction of rams. Anim. Reprod. Sci. 3, 125-132. doi:10.1016/0378-4320(80) 90039-1

Martin, G. B., Rodger, J., and Blache, D. (2004). Nutritional and environmental effects on reproduction in small ruminants. Reprod. Fertil. Dev. 16, 491-501. doi:10.1071/RD04035

McPherson, N. O., Bell, V. G., Zander-Fox, D. L., Fullston, T., Wu, L. L., Robker, R. L., and Lane, M. (2015). When two obese parents are worse than one! Impacts on embryo and fetal development. Am. J. Physiol. Endocrinol. Metab. 309, E568-E581. doi:10.1152/AJPENDO.00230. 2015

Nguyen, Q. N., Zerafa, N., Liew, S. H., Morgan, F. H., Strasser, A., Scott, C. L., Findlay, J. K., Hickey, M., and Hutt, K. J. (2018). Loss of PUMA protects the ovarian reserve during DNA-damaging chemotherapy and preserves fertility. Cell Death Dis. 9, 618. doi:10.1038/S41419-018 0633-7

Onda, K., Tong, S., Beard, S., Binder, N., Muto, M., Senadheera, S. N., Parry, L., Dilworth, M., Renshall, L., Brownfoot, F., Hastie, R., Tuohey, L., Palmer, K., Hirano, T., Ikawa, M., Kaitu'u-Lino, T., and Hannan, N. J. (2017). Proton pump inhibitors decrease soluble fms-like tyrosine kinase-1 and soluble endoglin secretion, decrease hypertension, and 
rescue endothelial dysfunction. Hypertension 69, 457-468. doi:10.1161/ HYPERTENSIONAHA.116.08408

Patton, G. C., Olsson, C. A., Skirbekk, V., Saffery, R., Wlodek, M. E., Azzopardi, P. S., Stonawski, M., Rasmussen, B., Spry, E., Francis, K., Bhutta, Z. A., Kassebaum, N. J., Mokdad, A. H., Murray, C. J. L., Prentice, A. M., Reavley, N., Sheehan, P., Sweeny, K., Viner, R. M., and Sawyer, S. M. (2018). Adolescence and the next generation. Nature 554, 458-466. doi:10.1038/NATURE25759

Pringle, K. G., Kind, K. L., Sferruzzi, A. N., Thompson, J. G., and Roberts, C. T. (2010). Beyond oxygen: complex regulation and activity of hypoxia inducible factors in pregnancy. Hum. Reprod. Update 16, 415-431. doi:10.1093/HUMUPD/DMP046

Prokopuk, L., Stringer, J. M., Hogg, K., Elgass, K. D., and Western, P. S. (2017). PRC2 is required for extensive reorganization of H3K27me3 during epigenetic reprogramming in mouse fetal germ cells. Epigenetics Chromatin 10, 7. doi:10.1186/S13072-017-0113-9

Prokopuk, L., Hogg, K., and Western, P. S. (2018a). Pharmacological inhibition of EZH2 disrupts the female germline epigenome. Clin. Epigenetics 10, 33. doi:10.1186/S13148-018-0465-4

Prokopuk, L., Stringer, J. M., White, C. R., Vossen, R. H. A. M., White, S. J., Cohen, A. S. A., Gibson, W. T., and Western, P. S. (2018b). Loss of maternal EED results in postnatal overgrowth. Clin. Epigenetics 10, 95. doi:10.1186/S13148-018-0526-8

Roberts, C. T. (2010). IFPA Award in Placentology Lecture: complicated interactions between genes and the environment in placentation, pregnancy outcome and long term health. Placenta 31, S47-S53. doi:10. 1016/J.PLACENTA.2010.01.001

Robertson, D. M., de Vos, F. L., Foulds, L. M., McLachlan, R. I., Burger, H. G., Morgan, F. J., Hearn, M. T., and de Kretzer, D. (1986). Isolation of a $31 \mathrm{kDa}$ form of inhibin from bovine follicular fluid. Mol. Cell. Endocrinol. 44, 271-277. doi:10.1016/0303-7207(86)90133-4

Robertson, S. A., Prins, J. R., Sharkey, D. J., and Moldenhauer, L. M. (2013). Seminal fluid and the generation of regulatory $\mathrm{T}$ cells for embryo implantation. Am. J. Reprod. Immunol. 69, 315-330. doi:10.1111/AJI.12107

Robker, R. L., Hennebold, J. D., and Russell, D. L. (2018). Coordination of ovulation and oocyte maturation: a good egg at the right time. Endocrinology 159, 3209-3218. doi:10.1210/EN.2018-00485

Rolnik, D. L., Wright, D., Poon, L. C., O’Gorman, N., Syngelaki, A., de Paco Matallana, C., Akolekar, R., Cicero, S., Janga, D., Singh, M., Molina, F. S., Persico, N., Jani, J. C., Plasencia, W., Papaioannou, G., TenenbaumGavish, K., Meiri, H., Gizurarson, S., Maclagan, K., and Nicolaides, K. H. (2017). Aspirin versus placebo in pregnancies at high risk for preterm preeclampsia. N. Engl. J. Med. 377, 613-622. doi:10.1056/ NEJMOA1704559
Smith, G. C. S. (2018). The STRIDER trial: one step forward, one step back. Lancet Child Adolesc. Health 2, 80-81. doi:10.1016/S2352-4642(17) 30176-1

Tervit, H. R., Whittingham, D. G., and Rowson, L. E. A. (1972). Succesful culture in vitro of sheep and cattle ova. J. Reprod. Fertil. 30, 493-497. doi:10.1530/JRF.0.0300493

Trott, J. F., Simpson, K. J., Moyle, R. L., Hearn, C. M., Shaw, G., Nicholas, K. R., and Renfree, M. B. (2003). Maternal regulation of milk composition, milk production, and pouch young development during lactation in the tammar wallaby (Macropus eugenii). Biol. Reprod. 68, 929-936. doi:10.1095/BIOLREPROD.102.005934

Trounson, A., and Mohr, L. (1983). Human pregnancy following cryopreservation, thawing and transfer of an eight-cell embryo. Nature 305, 707709. doi:10.1038/305707A0

Trounson, A. O., Leeton, J. F., Wood, C., Webb, J., and Wood, J. (1981). Pregnancies in humans by fertilization in vitro and embryo transfer in the controlled ovulatory cycle. Science 212, 681-682. doi:10.1126/SCI ENCE.7221557

Walters, J. L. H., De Iuliis, G. N., Dun, M. D., Aitken, R. J., McLaughlin, E. A., Nixon, B., and Bromfield, E. G. (2018). Pharmacological inhibition of arachidonate 15-lipoxygenase protects human spermatozoa against oxidative stress. Biol. Reprod. 98, 784-794. doi:10.1093/ BIOLRE/IOY058

Wen, J., Jiang, J., Ding, C., Dai, J., Liu, Y., Xia, Y., Liu, J., and Hu, Z. (2012). Birth defects in children conceived by in vitro fertilization and intracytoplasmic sperm injection: a meta-analysis. Fertil. Steril. 97, 13311337.e4. doi:10.1016/J.FERTNSTERT.2012.02.053

Western, P. S. (2018). Epigenomic drugs and the germline: collateral damage in the home of heritability? Mol. Cell. Endocrinol. 468, 121133. doi:10.1016/J.MCE.2018.02.008

Whittingham, D. G. (1968). Fertilization of mouse eggs in vitro. Nature 220, 592-593 doi:10.1038/220592A0

Winship, A. L., Stringer, J. M., Liew, S. H., and Hutt, K. J. (2018). The importance of DNA repair for maintaining oocyte quality in response to anti-cancer treatments, environmental toxins and maternal ageing. Hum. Reprod. Update. doi:10.1093/HUMUPD/DMY002

Xiao, S., Coppeta, J. R., Rogers, H. B., Isenberg, B. C., Zhu, J., Olalekan, S. A., McKinnon, K. E., Dokic, D., Rashedi, A. S., Haisenleder, D. J., Malpani, S. S., Arnold-Murray, C. A., Chen, K., Jiang, M., Bai, L., Nguyen, C. T., Zhang, J., Laronda, M. M., Hope, T. J., Maniar, K. P., Pavone, M. E., Avram, M. J., Sefton, E. C., Getsios, S., Burdette, J. E., Kim, J. J., Borenstein, J. T., and Woodruff, T. K. (2017). A microfluidic culture model of the human reproductive tract and 28-day menstrual cycle. Nat. Commun. 8, 14584. doi:10.1038/NCOMMS14584 